\title{
Real Time Forest Anti-Smuggling Monitoring System based on IOT using GSM
}

\author{
Pushpalatha $\mathbf{R}^{1}$, Darshini M.S ${ }^{2}$ \\ Assistant Professor, Dept of CS\&E, VTU PG Centre, Mysuru, India ${ }^{1}$ \\ M.Tech, Dept of CS\&E, VTU PG Centre, Mysuru, India ${ }^{2}$
}

\begin{abstract}
The motivation behind this task work is to plan an enemy of pirating framework which is valuable in Protected Forest regions. The Theft and illicit development of business trees like Sandalwood, Teak, Sagwan., and so on have been a noteworthy concern. It is additionally a burglary to Forest Flora and fauna. As concerned residents our belief system is to counteract such sneaking exercises by utilizing most recent advances. These trees are exorbitant and also less accessible on the planet. These are use in the medicinal sciences and in addition beauty care products. In light of titanic dimension of money related with offering of such tree woods piles of events are going on of cutting of trees and their sneaking. To join such appropriating and to save the forested spaces the world over some preventive evaluations ought to be passed on. We are ending up such a structure which can be used to tie this appropriating.
\end{abstract}

Keywords: Accelerometer sensor, flex sensor, fire sensor, GPRS, GSM Module, GPS, Cloud

\section{INTRODUCTION}

For ages we have been perturbed by illegal activities like smuggling of Precious and commercial trees such as Teakwood, Sandalwood, Sagwan etc., from the protected Forest areas. These trees are very expensive and have a lot of commercial demand in the world market. The trees are generally considered to be protected by marking them some tags manually.This will not be useful and reliable since anyone can hamper it. Also during Natural calamities trees may somehow get damaged.

A SMART automated unit has been thus devised to tackle these issues. The Combination of Latest Wireless communication systems and Embedded solutions offer us such modules. The Module is intended to operate in a particular area and this Module will consist of two Units:

11) Tree Unit

12) Main Server Unit (base station).

Each Tree should have one little Embedded System-Unit with: Renesas Microcontroller, Sensors, GPRS and Solar power. The nearness of above said parts will send the current state of the tree to the Base station, utilizing GPRS module. The information sent by GPRS is as information string/outline by means of Internet, henceforth IoT organize is shaped here. The information outline is deciphered by the Server at the Base Station. The Base station has a server which keeps up the database of every single such tree. The correspondence to construct station is situated in light of most recent innovation utilizing Amazon Web Services. DotNet is the product utilized in the Server to interpret the gotten information outline shape the Trees in the woodland.

At the principle server just approved individual will approach the database. The database is investigated to check whether the tree is sheltered or being pulled away. Anyway the database keeps constantly refreshing about the current state of trees and crisis circumstances should be gone to by the Forest specialists. For instance if the tree is fallen the "Flex Sensor" information will be an extraordinary incentive than the typical set limit esteem.

\section{LITERATURE SURVEY}

The idea of Commercial and Precious tree insurance and keeping their burglary is the prime thought of this proposition and that excessively utilizing most recent advances. The thoughts are obviously characterized in [1] Against Passing on System for Trees in Forest utilizing Flex Sensor and Zigbee. This paper discloses concerning how to confine the carrying exercises and to spare the woods zones on Earth utilizing some preventive measures. The framework that was produced www.iosrjournals.org utilizing a small scale Sensor organize utilizing zigbee module, Flex sensor , GSM Module and GPS utilizing the stage of Visual Basic. 


\section{IJARCCE}

Vol. 8, Issue 2, February 2019

The idea has been further strengthned in [2] Preventive System for Forests Volume 4 Issue 1, Jan - Feb 2016, which discusses the primary three units to be utilized in the Module to be structured like Tree Unit, Area/Sub Server Unit and Server Unit. It focuses on Zigbee and GSM advances while keeping up the Server on VisualBasic. Android based Anti-Smuggling Module has been discussed in Anti-Smuggling Alarm System for Trees in Forest Using Android [3]. Using accelerometers and temperature sensors framing a smaller than expected sensor organizing is presented here. Likewise Android based idea is extremely perfect for current situation since every single Mobile handset are Android based. The counter carrying squad can quickly get messages on their handsets amid any interference to the trees. Accelerometers depend on MEMS Technology - Micro Electro Mechanical Systems [4].The paper in subtle elements examines on MEMS accelerometer which is additionally alluded as vertical capacitive torsional accelerometer (TXL).

\section{ARCHITECTURE}

Examines about the Method in which this Module is planned in Fig.1. The Module created is a joining of equipment and programming. The equipment is created utilizing sensors - Temperature Sensor, Flex Sensor and Accelerometer.

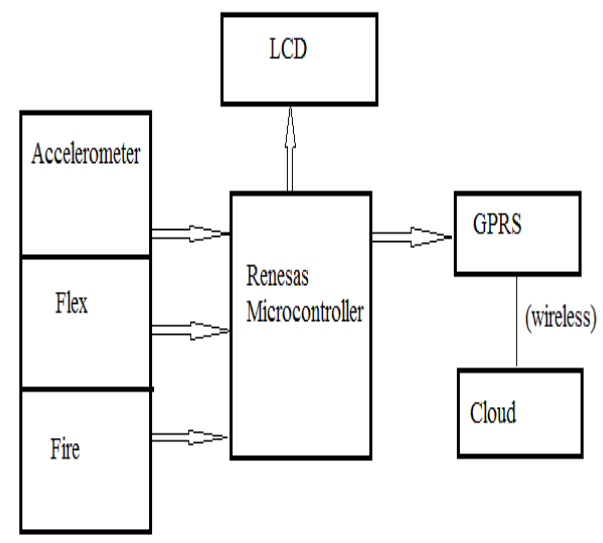

Fig 1: Proposed framework Block Diagram

Renesas microcontroller is the core of the framework, situated at the focal point of the square graph and controls every one of the activities of the framework. A LCD is utilized to show every one of the tasks going ahead inside the microcontroller, this unit would comprise of three sensors to give the data of getting Cut Down the trees, Damage with flame, and so on. The tree unit would be the standard unit for the utilization of the structure. The tree unit joins three sensors; Accelerometer Sensors, flex sesnsor, LM35 Sensor. These sensors would be attentive in order to send the data to the controller on the tree unit which would be then transmitted to the running with stage for instance Tree Unit to the tree unit which has GSM module,for further getting ready to Base station. This is the second and last time of the structure which would being charge of get-together the information and encourage the equivalent to the Main-Server Unit.

The tree unit is mindful to have the data from various Tree Units. Tree cutting will be identified by accelerometer sensor and any tree limbs are twist at a developing time Accelerometer sensor is send the data to tree unit, and temperature sensor is utilized to send the encompassing of the temperature to controller unit and GSM module. All the data send through GSM to Admin Mobile. With the assistance of GSM modem at whatever point any tree will get scratch down then we get the SMS on our selected telephone which contains tree data.

\section{SENSOR SELECTION}

The sensors resemble an organ arrangement of this unit since they are ones which anticipate or educate about the tree's condition. In spite of the fact that little in size their ability to detect the earth around them like temperature, dampness and so on., make them most imperative piece of any unit. Thus we require sensors that are solid and rough, in the meantime they ought to be sparing. For the Hardware structure here 3 sensors has been chosen.

- $\quad$ Temperature sensor-LM35

- $\quad$ Flex sensor-TO sense the tress's bending movement

- Accelerometer-ADXL335-To sense the 3 axes movement of the tree 


\section{IJARCCE}

A. LM35

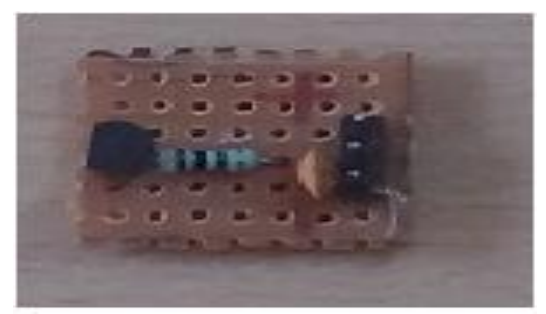

Fig 2:Temperature Sensor

The LM35 arrangement are accuracy incorporated circuit temperature gadgets with a yield voltage directly relative to the Centigrade temperature. The low-yield impedance, straight yield, and correct natural arrangement of the LM35 contraption makes interfacing to readout or control equipment especially basic. The LM35 temperature sensor is utilized to identify exact centigrade temperature. The yield of this sensor changes depicts the linearity. The o/p voltage of this IC sensor is straightly relative to the Celsius temperature.

The working voltage scope of this LM35 ranges from $-55^{\circ}$ to $+150^{\circ} \mathrm{C}$ and it has low-self warming. This is worked under 4 to 130 volts. Temperature sensor circuit has terminals for example ,two sources of info like non-upsetting (+) and modifying (-) and just a single yield pin.

This LM35 temperature sensor circuit enhance the contrast between its information terminals. The benefits of temperature sensor incorporate. It has no impact on the medium, more exact, It has an effectively molded yield and It reacts in a split second.

\section{B. FLEX SENSOR}

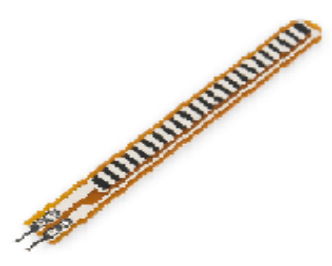

Fig 3: Conductive Link Based Flex Sensor

A flex sensor or curve sensor is a sensor that estimates the measure of avoidance or bending.The obstruction of the flex sensor increments as the body of the part bends.A flex sensor can be utilized with a microcontroller to recognize or measure bowing. As its name recommends, a conductive ink-based flex sensor utilizes an extraordinary ink whose opposition fluctuates when bowed. The ink may contain carbon or silver to make it conductive. The dispersing between carbon particles are bigger when twisted and closer when straight which results in a difference in resistance.

These sensors will resemble $30 \omega$ resistor. As it twists, the opposition between the two terminals will increment to as much as $70 \mathrm{k} \omega$ at a $90^{\circ}$ edge. By joining the flex sensor with a static resistor to make a voltage divider, you can create a variable voltage that can be perused by a microcontroller's simple to-computerized converter

C. ADXL335

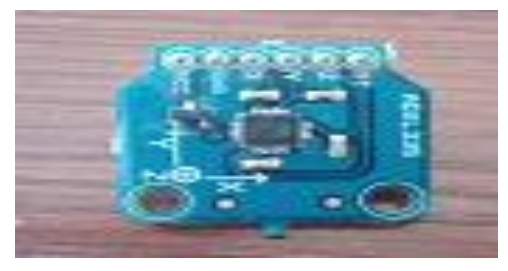

Fig 4: ADXL335 Module 3-hub Analog Output Accelerometer

An accelerometer is an electromechanical gadget used to gauge speeding up powers.Such powers might be static, similar to the nonstop power of gravity or, just like the case with numerous cell phones, dynamic to detect development or vibrations. Quickening is the estimation of the adjustment in speed or speed isolated by time. Accelerometers enable the client to comprehend the surroundings of a thing better. With this little gadget, you can 


\section{IJARCCE}

Vol. 8, Issue 2, February 2019

decide whether a question is moving tough, regardless of whether it will fall over in the event that it tilts any more,or whether it's flying on a level plane or calculating descending the accelerometer comprises of a wide range of parts and works from numerous points Of view,two of which are the piezoelectric impact and the capacitance sensor. The piezoelectric impact is the most widely recognized type of accelerometer and utilizations minute gem structures that end up worried because of accelerative powers. These gems make a voltage from the pressure, and the accelerometer translate the voltage to decide speed and introduction. The capacitance accelerometer detects changes in capacitance between microstructures situated alongside the gadget. On the off chance that an accelerative power moves one of these structures, the capacitance will change and the accelerometer will make an interpretation of that capacitance to voltage for translation.

\section{COMPONENTS}

\section{A. Microcontroller R5F102AA}

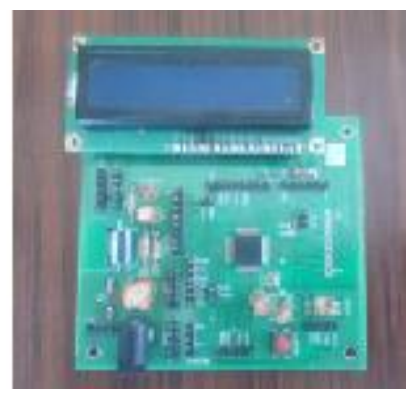

Fig 5:Renesas RL78 Series Development Board

A microcontroller is a conservative coordinated circuit intended to administer a particular activity in an inserted framework. A run of the mill microcontroller incorporates a processor, memory and information/yield(I/O) peripherals on a solitary chip.A Microcontroller is an IC chip that executes programs for controlling different gadgets or machines.The microcontroller Board in Fig.5 ought to be conservative and ought to have inbuilt ADC to detect the yields of different sensors. It ought to likewise be rough, devour less power and efficient. Consequently the most recent microcontroller from Renesas hardware - RL78 arrangement R5F1022AA - a 64 stick is chosen. The RL78 Renesas MicroController Series offers architects the Gen-next plan execution with lessening framework control, improving combination and arrangement for a financially savvy platform. They are additionally accessible in broad scope of little bundles and with working temperature go from - 40Deg to +85Deg

.Renesas is most recent microcontroller family that offers superior element with uncommonly low power utilization over a wide and flexible stretch out of things. This microcontroller offers rich utilitarian security and installed wellbeing qualities required for new and progressed car applications. The center structure of microcontroller CPU bolster high dependability and superior prerequisites. The Renesas microcontroller offering low influence,superior, unobtrusive bundles and the biggest scope of memory sizes joined together with qualities rich peripherals.

\section{B. Liquid Crystal Display}

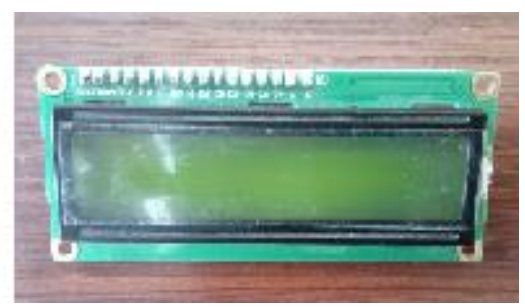

Fig 6:16X2 LCD Display

A LCD, or Liquid Crystal Display, is a kind of screen that is utilized in numerous PCs, TVs, computerized cameras, tablets, and PDAs. LCDs are thin yet are really made out of a few layers. Those layers incorporate two spellbound boards, with a fluid gem arrangement between them. Light is anticipated through the layer of fluid precious stones and is colorized, which creates the noticeable image.JHD162A is the LCD which is interfaced to the microcontroller. It works under $+5 \mathrm{~V}$ supply go. It goes about as a showcase unit and furthermore fills in as a testing unit amid programming advancement stage. The Panel of this LCD has 2 lines and 16 segments. The fluid has a special preferred standpoint of Having low power utilization than the LED or cathode beam tube. Fluid precious stone 


\section{IJARCCE}

Vol. 8, Issue 2, February 2019

showcase screen chips away at the rule of blocking light as opposed to transmitting light. LCD's requires backdrop illumination as they don't discharges light by them.

The premise of LCD innovation is the fluid gem, a substance made of convoluted atoms. Like water, fluid precious stones are strong at low temperatures. Additionally like water, they soften as you warm them. Be that as it may, when ice dissolves, it changes into an unmistakable, effortlessly streaming fluid. Fluid precious stones, be that as it may, change into a shady fluid altogether different from fluids like water, liquor, or cooking oil. At marginally higher temperatures, the darkness vanishes, and they look much like some other fluid.

\section{GPRS}

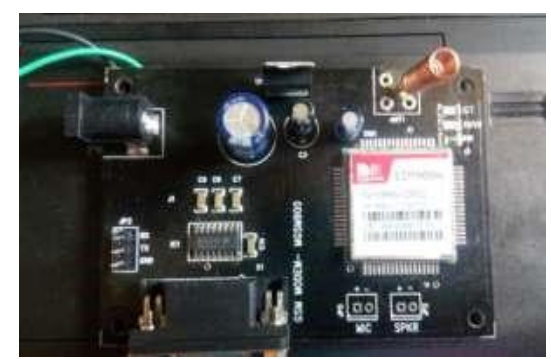

Fig 7:General Packet Radio Service

General Packet Radio Services(GPRS)is a bundle based remote correspondence benefit that guarantees information rates from 56 up to $114 \mathrm{Kbps}$ and constant association with the Internet for cell phone and PC clients.The higher information rates enable clients to participate in video meetings and collaborate with media Web destinations and comparative applications utilizing portable handheld gadgets and note pad PCs. GPRS depends on Global System for Mobile (GSM) correspondence and supplements existing administrations such circuit-exchanged wireless associations and the Short Message Service (SMS).GPRS is an administration inside the GSM arrange, much the same as the two most well known administrations SMS and voice associations.

GPRS is utilized for transmitting information in the GSM organize in from of packets.GPRS is interfaced to UART0 of the Microcontroller board. Directions for GPRS are sent through UART as sequential information to the GPRS module.GPRS chips away at a similar method like GSM organize, however, has additional components that allow divide transmission. This data mastermind covers a second-age GSM sort out giving package data transport at the rates from 9.6 to $171 \mathrm{kbps}$. GPRS innovation brings various advantages for clients and system administrators alike over the essential GSM framework. It was broadly conveyed to give a reasonable information capacity by means of cell media communications innovation. GPRS gives you a chance to remain associated as Information can be sent or gotten instantly as the need emerges, contingent upon the quality and inclusion likewise gives versatile application engineers a chance to create more up to date, quicker and better portable applications that haven't been accessible because of past innovation speed restrictions.

\section{GSM-Modem}

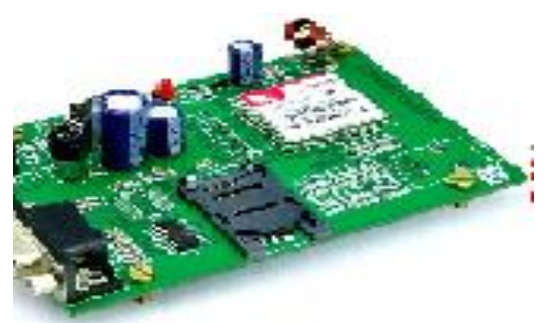

Fig 8:global system for mobile communication

GSM is an open and advanced cell innovation utilized for transmitting versatile voice and information administrations works at the $850 \mathrm{MHz}, 900 \mathrm{MHz}, 1800 \mathrm{MHz}$ and $1900 \mathrm{MHz}$ recurrence groups. GSM framework was produced as a computerized framework utilizing time division numerous entrance(TDMA) procedure for correspondence reason. A GSM digitizes and decreases the information, at that point sends it down through a channel with two unique floods of customer information, each in its own specific schedule vacancy. The advanced framework has a capacity to convey 64 kbps to 120 Mbps of information rates. 


\section{IJARCCE}

Vol. 8, Issue 2, February 2019

A GSM modem can likewise be a standard GSM cell phone with the fitting link and programming driver to associate with a sequential port or USB port on your PC. GSM modem is generally desirable over a GSM cell phone. The GSM modem has wide scope of utilizations in exchange terminals, store network the executives, security applications, climate stations and GPRS mode remote information logging. The portable station comprises of the versatile hardware, for example the handset, and a brilliant card called the Subscriber Identity Module(SIM). The SIM gives individual portability, with the goal that the client can approach bought in administrations regardless of a particular terminal. By embeddings the SIM card into another GSM terminal, the client can Get and make calls from that terminal, and get other bought in services. There are different cell sizes in a GSM framework, for example, full scale, smaller scale, pico and umbrella cells. Every cell differs according to the usage area. There are five diverse cell sizes in a GSM organize large scale ,small scale, pico and umbrella cells. The inclusion territory of every cell fluctuates as indicated by the usage condition. GSM modem properly interfaced to the MC through the dimension shifter IC Max232. The SIM card mounted GSM modem after getting digit order by SMS from any wireless send that information to the MC through sequential correspondence. While the program is executed, the GSM modem gets order 'STOP' to build up a yield at the MC, the contact purpose of which are utilized to debilitate the start switch. The order so sent by the client depends on an implication gotten by him through the GSM modem'ALERT' a customized message just if the information is driven low. The total task is shown over $16 \times 2$ LCD show.

\section{WORKING TECHNIQUE}

In monstrous woodlands, each tree will have sensors unit which is fitted on stem of tree will chat with their essential server unit. The correspondence between tree unit and central server unit happen by using GSM module. The server will have Microsoft Visual Basic which will open the Google maps in establishment and exhibit the territory of taking and it other than gives the information in prohibited arrangement with as a rule examination of tree.it give area scope and longitude by utilizing GPS. To give realtime web based checking and Internet of Things (IoT) capacity, the framework gathers and transfers sensor information to the cloud through GPRS web availability with the assistance of AT directions in blend with HTTP GET strategy. Besides, the framework sends message caution to the dependable organ through GSM/GPRS organize and a SMS entryway benefit is implemented. With the assistance of GSM modem at whatever point any tree will get cleave down then we get the sms on our picked mobile.After getting sms on picked telephone which contains data concerning Area name, Tree Name, Longitude and Latitude of the tree district from these data we can follow zone and limit the sneaking.

\section{DEMONSTRATION}

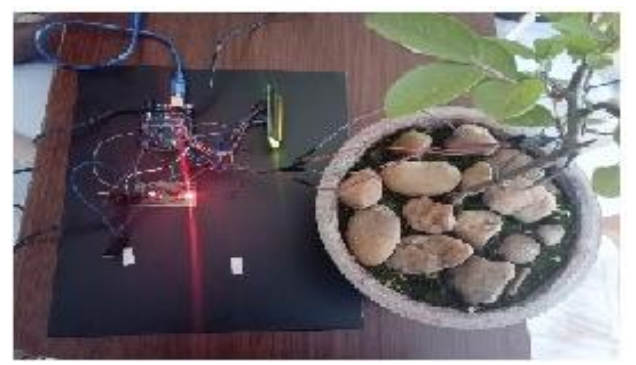

Fig 9:Hardware set-up

A prototype module will be developed for the project.To demonstrate the scenario of Tree smuggling in a Protected Forest environment the above hardware set-up is made. A small toy tree with all the 3 sensors - Accelerometer, Flex sensor and Temperature sensor - attached is interfaced to the microcontroller. Tree cutting will be detected by accelerometer sensor and any tree bend or tree branches and Tree Cutting.Forest surrounding temperature will find the temperature sensor.All the information will send to cloud server through GSM module.

\section{CONCLUSION AND FUTURE SCOPE}

\section{A. Conclusion}

The theory was completed to abstain from carrying of valuable trees in secured zone in woods. There are numerous approaches to secure trees yet here a brilliant technique for interfacing a few sensors around trees with a microcontroller was done. The most recent technique for distributed computing utilizing Amazon web administrations 


\section{IJARCCE}

Vol. 8, Issue 2, February 2019

was executed which goes about as a server for acquiring the tree status remotely. That is to imply the Forest specialists about the trees' condition on $24 \times 7$ basis. This was conceivable in light of the fact that the inserted unit has GPRS. Thought was to regard each tree as a Smart tree (with a microcontroller, sensors and GPRS) and bringing numerous such trees under a system (Internet of Things). Anyway the Trees' condition is under ceaseless observing as a result of sensors. Subsequently it's an amalgamation of IoT, WSN and AWS to ensure the Nature.

In along these lines we are building up the structure which arranged to limit the sneaking of tree in backwoods where the individual not set up to give security. Such structure we are making in the backwoods where the tree are exorbitant and theirsecurity is basic reality. Here we are give such sort of system. We are growing such a framework which can be utilized to confine the carrying of the trees which would thusly stop the de-forestation and keep up the Environmental equalization which would comprehend one of the issues with the Global Warming predominantly utilized in backwoods.

\section{B. Future Scope}

Though the claim has been made that a Smart module has been developed to protect trees, future enhancements are required to make the system more rugged.

-The Units / Hardware / Sensors have to be rugged.

-Suitable enclosure has to be made.

-The Module should be placed in untraceable place on trees, not easily accessible to tree-destructors.

- Forest Authorities has to be suitably educated.

\section{REFERENCES}

[1]. Anti Smuggling System for Trees in Forest using Flex Sensor and Zigbee International Journal of Advanced Research in Computer Engineering \& Technology (IJARCET) Volume 3, Issue 9,September 2014 Narhari R. Kotkar M.E.(ESD And VLSI)

[2]. Preventive System for Forests -International Journal of Computer Science Trends and Technology (I JCST) - Volume 4 Issue 1, Jan - Feb 2016Prasad R. Khandar, K. Deivanai, M.Tech, Assistant Professor, School of Computer Science and Engineering VIT University, Chennai Campus - Tamil Nadu - India

[3]. Development and analysis of the vertical capacitive accelerometer InnamLeea, Gil HoYoona, Jungyul Parka, SeonhoSeokb, KukjinChunb, KyoIl Leea,* a School of Mechanical and Aerospace Engineering, Seoul National University, San 56-1, ShilimDong, Kwanak-Gu, Seoul, South Koreab School of Electrical Engineering and Computer Science, Seoul National University, Seoul, South KoreaReceived Available online 11 November 2004

[4]. Innovative Protection of Valuable Trees fromSmuggling Using RFID and Sensors International Journal of Innovative Research in Science,Engineering and TechnologyVol. 6, Issue 3, March 2017 Dept. of EEE, Vel Tech High Tech Dr.RangarajanDr.Sakunthala Engineering College, Avadi,Chennai, India

[5].http://esl.fis.edu/students/bolster/sci/content/stolenforest.htMazidi, RolnD.Mckenley, "The 8051 Microcontroller and embedded system using assembly \& Cl.

[6]. Yichang, China; GuangyuHe ;Junli Wan — Research on Zigbee wireless communication technology Wei Wang\| In Electr.Eng. \& Renewable Energy Sch., China Three Gorges University.

[7]. Chonggang Wang, Tao Jiang, Qian Zhang —ZigBee® Network Protocols and Applications\|

[8]. ZigBee Alliance, ZigBee Specification. Version 1.0ZigBee Document 053474r06 